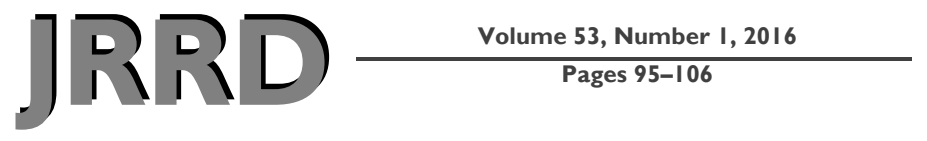

\title{
Potential neurobiological benefits of exercise in chronic pain and posttraumatic stress disorder: Pilot study
}

\author{
Erica Scioli-Salter, PhD; ${ }^{1-3^{*}}$ Daniel E. Forman, MD; ${ }^{4-5}$ John D. Otis, PhD; ${ }^{2-3,6}$ Carlos Tun, MD; ${ }^{7}$ Kelly Allsup, \\ BS; ${ }^{2,4}$ Christine E. Marx, MD; ${ }^{8}$ Richard L. Hauger, MD; ${ }^{9}$ Jillian C. Shipherd, PhD; ${ }^{1-3}$ Diana M. Higgins, PhD; ${ }^{2-3}$ \\ Anna Tyzik, BS; ${ }^{1}$ Ann M. Rasmusson, MD $^{1,3}$ \\ ${ }^{1}$ Women's Health Sciences Division, National Center for Posttraumatic Stress Disorder, and ${ }^{2}$ Research Service, Department \\ of Veterans Affairs (VA) Boston Healthcare System, Boston, MA; ${ }^{3}$ Department of Psychiatry, Boston University School of \\ Medicine, Boston, MA; ${ }^{4}$ Geriatrics, Research, Education and Clinical Center, VA Pittsburgh Healthcare System, Pitts- \\ burgh, PA; ${ }^{5}$ Division of Cardiovascular Medicine, VA Boston Healthcare System, Boston, MA; and Division of Cardiovas- \\ cular Medicine, Brigham and Women's Hospital, Harvard Medical School, Boston, MA; ${ }^{6}$ Department of Psychological and \\ Brain Sciences, Boston University, Boston, MA; ${ }^{7}$ Division of Rehabilitative Medicine, Harvard Medical School, Boston, \\ MA; and Division of Rehabilitative Medicine, VA Boston Healthcare System, Boston, MA; ${ }^{8}$ Duke University School of Med- \\ icine, Durham VA Medical Center, Durham, NC; and VA Mid-Atlantic Mental Illness Research, Education and Clinical \\ Center, Durham, NC; ${ }^{9}$ Center of Excellence for Stress and Mental Health, VA San Diego Healthcare System, San Diego, \\ CA; and Department of Psychiatry, School of Medicine, University of California San Diego, La Jolla, CA
}

\begin{abstract}
This pilot study assessed the effects of cardiopulmonary exercise testing and cardiorespiratory fitness on plasma neuropeptide Y (NPY), allopregnanolone and pregnanolone (ALLO), cortisol, and dehydroepiandrosterone (DHEA), and their association with pain sensitivity. Medication-free traumaexposed participants were either healthy $(n=7)$ or experiencing comorbid chronic pain/posttraumatic stress disorder (PTSD) $(n=5)$. Peak oxygen consumption $\left(\mathrm{VO}_{2}\right)$ during exercise testing was used to characterize cardiorespiratory fitness. Peak $\mathrm{VO}_{2}$ correlated with baseline and peak NPY levels $(r=0.66$, $p<0.05$ and $r=0.69, p<0.05$, respectively), as well as exercise-induced changes in ALLO $(r=0.89, p<0.001)$ and peak ALLO levels $(r=0.71, p<0.01)$. NPY levels at the peak of exercise correlated with pain threshold $30 \mathrm{~min}$ after exercise $(r=0.65, p<0.05)$, while exercise-induced increases in ALLO correlated with pain tolerance $30 \mathrm{~min}$ after exercise $(r=0.64$, $p<0.05)$. In contrast, exercise-induced changes in cortisol and DHEA levels were inversely correlated with pain tolerance after exercise $(r=-0.69, p<0.05$ and $r=-0.58, p<0.05$, respectively). These data suggest that cardiorespiratory fitness is associated with higher plasma NPY levels and increased ALLO responses to exercise, which in turn relate to pain sensitivity. Future work will examine whether progressive exercise training increases cardiorespiratory fitness in association with increases
\end{abstract}

in NPY and ALLO and reductions in pain sensitivity in chronic pain patients with PTSD.

Abbreviations: ALLO = allopregnanolone and pregnanolone, $\mathrm{ANOVA}=$ analysis of variance, $\mathrm{BMI}=$ body mass index, $\mathrm{CPT}=$ cold pressor test, $\mathrm{CPX}=$ cardiopulmonary exercise testing, $\mathrm{CSF}=$ cerebrospinal fluid, $\mathrm{CSU}=$ clinical studies unit, $\mathrm{CV}=$ coefficient of variation, DHEA = dehydroepiandrosterone, DHEA $(\mathrm{S})=$ DHEA-sulfate, DSM-IV = Diagnostic and Statistical Manual of Mental Disorders-4th Edition, EKG = electrocardiogram, GABA = gamma-aminobutyric acid, GC-MS = gas chromatography-mass spectrometry, IV = intravenous line, $\mathrm{NPY}=$ neuropeptide $\mathrm{Y}, \mathrm{OEF}=$ Operation Enduring Freedom, OIF $=$ Operation Iraqi Freedom, PTSD = posttraumatic stress disorder, $\mathrm{RIA}=$ radioimmunoassay, $\mathrm{TC}=$ trauma-exposed healthy control, $\mathrm{VA}=$ Department of Veterans Affairs, $\mathrm{VO}_{2}=$ oxygen consumption.

*Address all correspondence to Erica Scioli-Salter, PhD; VA Boston Healthcare System, Research Division, 150 South Huntington Ave, 116B-3, Boston MA 02130; 857364-5696. Email: Ericarose.scioli@va.gov http://dx.doi.org/10.1682/JRRD.2014.10.0267 
Key words: ALLO, biomarkers, cardiorespiratory fitness, chronic pain, exercise, neurosteroids, NPY, pain sensitivity, PTSD, $\mathrm{VO}_{2}$.

\section{INTRODUCTION}

Chronic pain and posttraumatic stress disorder (PTSD) are both disabling and health-threatening conditions that adversely affect the biological, psychological, and social domains of those affected and place a significant financial strain on the healthcare system [1]. Although reported rates vary, as many as 50 to 75 percent of patients who present for PTSD treatment also have a significant chronic pain condition [2-4]. Conversely, among persons presenting for treatment of chronic pain, approximately 20 to 37 percent have PTSD [5]. Furthermore, 80 percent of combat Veterans with PTSD report experiencing chronic pain [6]. While the relationship between chronic pain and PTSD has been observed across all combat theaters, it may be particularly strong among Operation Iraqi Freedom (OIF)/Operation Enduring Freedom (OEF) Veterans because the pain and PTSD conditions in these Veterans are more likely to have a recent onset and to be associated with the same traumatic event [7]. The most recent estimates from a study by Cifu et al. of a nationally representative sample of OIF/OEF/Operation New Dawn Veterans receiving care at Department of Veterans Affairs (VA) polytrauma clinics estimated prevalence rates of chronic pain to be approximately 42 percent [8] (as compared with $11 \%$ in the general population) [9]. PTSD rates were 29.4 percent (vs $8 \%$ in the general population) [2], and the comorbid chronic pain and PTSD rate was 12.6 percent. Despite the differences in these estimates, the strong relationship between chronic pain and PTSD is clear and the coprevalence of these conditions negatively affects the course of both disorders [1-2].

Research suggests that the relationship between chronic pain and PTSD is maintained by biological as well as psychosocial factors such as comorbid depression, anxiety sensitivity, poor perceived life control, and physical disability [9]. However, while biopsychosocial models of the relationship between chronic pain and PTSD have focused on different empirically supported aspects of the chronic pain-PTSD relationship (e.g., mutual maintenance, shared vulnerability, triple vulnerability, and fear avoidance models) [1-2,10-12], descriptions of the biological contribution are often limited. For example, vulnerability to increased physiological arousal is raised as a relevant pathophysiological process without a clear description of specific neurobiological factors involved. We suggest that to be truly consistent with a biopsychosocial model of illness, the mechanisms underlying the biological contribution to these two disorders should be further examined and delineated. Such an investigation could enable development of novel and more effective pharmacological and nonpharmacological treatments targeted to biological mechanisms that promote comorbid chronic pain and PTSD - treatments that could potentially be individually tailored. This is particularly compelling at a time when the VA is focused on developing alternatives to opiate-based treatments to reduce the effect of comorbid chronic pain and PTSD on the lives of Veterans.

As detailed in a recent review [13], potential pathophysiologic factors shared between chronic pain and PTSD include deficits in neuropeptide Y (NPY) and the neuroactive gamma-aminobutyric acid (GABA)-ergic steroids allopregnanolone and its equipotent stereoisomer pregnanolone (together termed ALLO) [14-20]. These antinociceptive and stress-buffering molecules have been found to be low in patients with PTSD and inversely correlated with PTSD symptom severity [14-25]. Given the known antinociceptive properties of NPY and ALLO $[15,17-18,20]$, these molecules also may be low in chronic pain populations exposed to trauma. Previous animal and human studies have shown that exposure to repeated, severe, or life-threatening stress is associated with reductions in resting plasma NPY levels, which are, in turn, associated with increased release of norepinephrine under stress [25]. It is not yet clear whether NPY responses to stress differ between trauma-exposed individuals with and without PTSD. Less is known about the role of trauma exposure versus PTSD vulnerability in relation to ALLO resting levels or stress reactivity. The study that demonstrated a strong correlation between low cerebrospinal fluid (CSF) levels of ALLO in women with PTSD and PTSD reexperiencing symptoms utilized a non-trauma-exposed comparison group [16].

In addition to these inhibitory central nervous system neurosteroids, it is important to consider other neuroactive steroids that are important to acute and long-term stress adaptation and that modulate the NPY and ALLO systems. For example, there is a glucocorticoid response element in the promoter of genes involved in both NPY and ALLO synthesis. Of note, cortisol is thought to be of benefit in acute pain conditions, although sustained high 
levels of cortisol have been found to play a role in chronic pain [26]. The androgen dehydroepiandrosterone (DHEA) is secreted at the same time as cortisol and negatively modulates $\mathrm{GABA}_{\mathrm{A}}$ receptor function while positively modulating excitatory N-methyl-D-aspartate receptor function. Thus, DHEA may acutely antagonize effects of ALLO in neuronal systems, consistent with the observation that higher CSF DHEA/ALLO ratios were associated with increased PTSD reexperiencing and negative mood symptoms in premenopausal women. On the other hand, DHEA also enhances the metabolism of cortisol to an inactive metabolite, and administration of DHEA has been associated both with reductions in plasma cortisol levels and increases in plasma ALLO levels, as well as relief of negative mood. In addition, a higher plasma DHEA to cortisol ratio has been shown to correlate negatively with PTSD and negative mood symptoms [27]. Thus, by including cortisol and DHEA in our preliminary investigation, we hoped to compare profiles of these interacting neuroendocrine factors between chronic pain/ PTSD and trauma-exposed healthy controls (TCs).

It is thus of interest that acute intense exercise induces NPY release in healthy humans [28-29] and that rodents show acute increases in plasma and brain allopregnanolone levels after acute swim stress [30-33]. Exercise is also known to increase vagal parasympathetic, as well as sympathetic, neurotransmission and thus has the potential to suppress proinflammatory pathways and thereby reduce pain [34]. We thus hypothesized that an acute exercise challenge test might serve as a method to acutely raise plasma NPY and ALLO levels and affect pain sensitivity, as well as delineate differences in NPY and ALLO physiology between a chronic pain/PTSD population and TCs. We hypothesized that (1) acute exercise-induced changes in NPY and ALLO would be positively correlated with cardiorespiratory fitness, as measured by peak oxygen consumption $\left(\mathrm{VO}_{2}\right)$ during exercise testing, as well as with pain threshold and tolerance after exercise testing, and that (2) baseline levels and reactivity of NPY and ALLO would be lower in the chronic pain/PTSD group than in TCs. Given the variety of interactions between cortisol, DHEA, ALLO, and NPY and the variability in findings for cortisol and DHEA across different pain and PTSD populations [27,35], we did not expect to see clear relationships between pain sensitivity and exercise-induced increases in cortisol or DHEA in this small pilot sample.

\section{METHODS}

\section{Participants}

Twelve participants with and without chronic pain and PTSD were included in this study of the effect of a single session of peak cardiopulmonary exercise testing (CPX) on plasma neurohormone levels (NPY, ALLO, cortisol, DHEA) and pain sensitivity. Seven participants comprised the TC group, and five participants comprised the chronic pain/PTSD group. Approximately 58.3 percent of the sample $(n=7)$ were male and 25 percent were Veterans $(n=3)$, all of whom were in the chronic pain/ PTSD group. Participants were of several races: African American (42\%), Caucasian (33\%), Asian (8\%), and other (Native American and Indian, 16.7\%).

Diagnostic evaluations were conducted by licensed healthcare professionals. The Clinician-Administered PTSD Scale, based on the Diagnostic and Statistical Manual of Mental Disorders-4th edition (DSM-IV) [36], was used to diagnose and score severity of PTSD. The Structured Clinical Interview for DSM-IV Axis I Disorders-Patient Edition [37] was administered to evaluate comorbid psychological disorders. A physical examination, routine laboratory testing, urine testing for illicit substances and cotinine (a by-product of nicotine), and an electrocardiogram (EKG) were administered to establish general health, confirm freedom from substance abuse, and establish safety for participation in the CPX. Chronic pain was established initially through participant selfreport of musculoskeletal pain for a minimum of 3 mo with an overall pain intensity of 4 or greater on a $0-10$ numerical pain rating scale. These participants were then evaluated by a rehabilitative medicine doctor and given an appropriate International Classification of Diseases9th Revision diagnosis for musculoskeletal pain, as well as medical clearance from a pain perspective for participation in exercise testing. All study participants were free of psychotropic medications for at least $6 \mathrm{wk}$ and free of pain medications for five half-lives ( $\sim 24 \mathrm{~h}$ in most cases) prior to testing.

\section{Experimental Procedures}

See the Appendix (available online only) for a flowchart of study procedures. Once eligibility was confirmed, participants presented for the exercise testing session at a clinical studies unit (CSU). The entire session took place between 8 a.m. and about 12 p.m. In addition to our stringent inclusion/exclusion criteria, participants were 
instructed to abstain from food and beverages, except for water, after midnight before testing. Upon arrival at the $\mathrm{CSU}$, the subjects were given water and power bars ( $6 \mathrm{kcal} / \mathrm{kg}$ ) to provide the same relative caloric load across participants. An intravenous line (IV) was placed and the "breakfast" provided $2 \mathrm{hr}$ before pre-exercise baseline blood sampling to ensure that stress and feeding-induced increases in adrenocorticotropic hormone, cortisol, glucose, and other reactants such as ALLO [32] had returned to baseline. During this time, participants completed nonprovocative self-report questionnaires about mood, pain interference, exercise motivation, and overall distress (results not reported in this article).

After baseline blood sampling, a cold pressor test (CPT) [38] was conducted to assess pain sensitivity prior to exercise. The CPT was repeated $30 \mathrm{~min}$ after CPX was completed. The CPT has been used widely in laboratory studies to measure pain perception and tolerance [39], as well as in investigations of the role of hypothalamicpituitary-adrenal axis activation in pain [40]. During the CPT, participants were instructed to hold their right hand still up to the wrist in temperature-controlled water $\left(4^{\circ} \mathrm{C}\right)$ inside the cold pressor apparatus. They were instructed to say when they first experienced pain and to withdraw the hand when the pain became intolerable. Two measures of pain sensitivity were derived: "pain threshold" and "pain tolerance." Pain threshold is defined as the number of seconds between hand immersion in the ice water and the first report of "pain" and is considered to correspond to physiological aspects of pain perception [39]. Pain tolerance is defined as the number of seconds between hand immersion and withdrawal from the water and is considered to correspond to the psychological aspects of pain perception. Finally, unknown to the participant, a maximum time limit of $7 \mathrm{~min}$ was imposed for safety purposes. A second blood draw was performed 15 min after the CPT, about 5 min before CPX.

CPX was performed in accordance with guidelines published by the American College of Cardiology [41]. Once ready for CPX, the participant was transported to the exercise testing room via wheelchair and transferred to the recumbent cycle ergometer. EKG electrodes were applied. The CPX was completed using a progressive staged cycle protocol, during which a ventilatory expired gas analysis system (MedGraphics BreezeSuite; St. Paul, Minnesota) was used to measure continuous gas exchange. Telemetry, blood pressure, and oxygen saturation were assessed for each subject $1 \mathrm{~min}$ prior to, during, and following the exer- cise test in standard clinical fashion. Peak $\mathrm{VO}_{2}$ was defined as the $30 \mathrm{~s}$ averaged value during the last stage of the CPX for use as the primary gauge of cardiorespiratory fitness. Ventilatory anaerobic threshold was also assessed as a measure of submaximal performance, determined as a $10 \mathrm{~s}$ average by the V-slope method [42]. All subjects achieved a peak respiratory exchange ratio of $\geq 1.05$, a standard indicator of adequate exercise effort. Blood was again collected via IV $5 \mathrm{~min}$ and $30 \mathrm{~min}$ after completion of exercise.

\section{Neurohormone Assays}

On the day of the CPX, collected blood was placed immediately on wet ice and spun within $15 \mathrm{~min}$ of collection in a refrigerated centrifuge for $15 \mathrm{~min}$. Plasma was then aliquotted into Eppendorf tubes for storage at $-80^{\circ} \mathrm{C}$ until assays were performed. Plasma concentrations of NPY were measured without extraction using a direct radioimmunoassay (RIA) kit (Euro-Diagnostica-ALPCO Diagnostics; Salem, New Hampshire). The assay sensitivity is $\sim 12.81 \mathrm{pg} / \mathrm{mL}$ and has $<0.1$ percent crossreactivity with $\mathrm{NPY}_{22-36}$, peptide YY, pancreatic polypeptide, and other neuropeptides. The intra-assay coefficient of variation $(\mathrm{CV})$ is 4.7 percent, and the interassay $\mathrm{CV}$ is 8.4 percent. Plasma levels of ALLO were measured by gas chromatography-mass spectrometry (GC-MS) after separation of the steroids by high-performance liquid chromatography using previously published methods [43-44]. ALLO levels were identified based on their GC-MS retention time characteristics; the definitive structural identification of each neurosteroid is provided by its unique mass fragmentation pattern. Only peaks with a signal-to-noise ratio greater or equal to 5:1 were integrated. The limit of neurosteroid detection with this method is $1 \mathrm{pg}$ (femtomolar sensitivity). Intra-assay CVs range between 2 and 7 percent for each neurosteroid. Concentrations of cortisol were measured by a solid-phase RIA (Siemens Healthcare Diagnostics; Deerfield, Illinois) with an intra-assay CV of approximately 4 percent and interassay $\mathrm{CV}$ of approximately 6 percent. The standard range is from 0.5 to $50 \mu \mathrm{g} / \mathrm{dL}$, with an assay sensitivity of $0.3 \mu \mathrm{g} / \mathrm{dL}$. Plasma concentrations of DHEA were measured by an RIA that requires no prior sample extraction (Beckman Coulter; Chino, California). The antiserum crossreacts 100 percent with DHEA but demonstrates low crossreactivity to other steroids potentially present in subject samples (e.g., crossreactivity to DHEA-sulfate [DHEA(S)] is $0.02 \%)$. The intra-assay $\mathrm{CV}$ is approximately 4 percent, while the interassay $\mathrm{CV}$ 
is approximately 7 percent. The standard working range is 0.2 to $24 \mathrm{ng} / \mathrm{mL}$, with a theoretical sensitivity of $0.06 \mathrm{ng} / \mathrm{mL}$.

\section{Data Analytic Plan}

The distributions of variables under investigation were tested for normality using the Kolmogorov-Smirnov test, and nonparametric statistical approaches were then employed as appropriate. Thus, to address hypothesis 1, Spearman rather than Pearson correlations were used. Plasma DHEA(S) levels were normalized by age because DHEA(S) levels are known to normally decline significantly over the age range of the study participants [45]. Levels of plasma NPY, ALLO, cortisol, and DHEA(S) were also normalized by body mass index (BMI) when correlated with peak $\mathrm{VO}_{2}$, which is expressed in milliliters per kilogram per minute. For initial correlations with pain sensitivity, absolute neuroactive hormone levels were used, given that the effect of these neuromodulators within local pain circuits or the brain would not be expected to vary by weight. However, given the absence of standards in the field for such analyses, we repeated these analyses using hormone levels normalized by weight. To address hypothesis 2 and test for the presence of group differences in hormone levels and responses to the CPX, repeatedmeasures analyses of variance (ANOVAs) were conducted with and without inclusion of BMI as a covariate. Finally, given the small size of this pilot sample, partial eta squared values were reported with each $F$-value in order to better estimate the strength of each finding. Such values were interpreted based on guidelines by Cohen [46]: $0.01=$ small; $0.06=$ medium; $0.13=$ large.

\section{RESULTS}

The mean age of the sample was $39.0 \pm 10.3 \mathrm{yr}$. In the pain/PTSD group, two participants had current comorbid major depression, one was diagnosed with simple phobia, one was diagnosed with generalized anxiety disorder, one was diagnosed with lifetime alcohol dependence, one was diagnosed with lifetime substance dependence, and two were diagnosed with a lifetime eating disorder. In the TC group, two participants met criteria for lifetime depression (episode) and one for lifetime alcohol abuse. No participants met criteria for a psychotic disorder. All were free of prescribed and illicit drugs, as well as alcohol, for a minimum of $4 \mathrm{wk}$ before participating in exercise testing, and all were free from significant medical illnesses. BMI was calculated using height and weight taken on the day of the exercise test session. For both groups combined, BMI ranged from 18.9 (normal weight) to 51.9 (obese class III), with a mean BMI of $34.9 \pm 9.92$ (obese class I). The two groups significantly differed in BMI: Mean $(\mathrm{M})_{\mathrm{TC}}=30.3 \pm 9.4$ (Obese class I), $\mathrm{M}_{\text {pain } / \mathrm{PTSD}}=41.5 \pm 6.8$ (obese class III); $t(10)=-2.41$, $p<0.05$. For both groups combined, $\mathrm{VO}_{2}$ ranged from 5.9 (very poor fitness) to 46.5 (excellent fitness), with a mean $\mathrm{VO}_{2}$ of 22.1 (poor fitness). The two groups did not significantly differ in $\mathrm{VO}_{2}: \mathrm{M}_{\mathrm{TC}}=24.8 \pm 13.2, \mathrm{M}_{\text {pain/PTSD }}=$ $18.3 \pm 4.8 ; t(10)=1.04, p=0.32$.

\section{Neuropeptide Y}

Figure 1(a) shows individual NPY levels for all participants across the four time points.

A repeated-measures ANOVA with GreenhouseGeisser corrections showed that NPY levels did not change significantly across time in this small sample $\left(F(1.31,11.74)=2.97, p=0.10\right.$; partial $\left.\eta^{2}=0.25\right)$, although there was a large effect size. There was not a significant difference in NPY levels between groups $\left(F(1,9)=0.33, p=0.58\right.$; partial $\left.\eta^{2}=0.04\right)$, nor was the time by group interaction significant $(F(1.31,11.74)=$ $0.15, p=0.77$, partial $\left.\eta^{2}=0.02\right)$. When the analysis was repeated using BMI as a covariate, the effect sizes were similar. For all study participants, there was a positive correlation between $\mathrm{VO}_{2}$ peak and NPY levels measured at baseline $(r=0.66, p<0.05)$ and peak exercise $(r=$ $0.69, p<0.05)$. NPY levels at peak exercise were positively correlated with pain threshold measured $30 \mathrm{~min}$ after exercise $(r=0.65, p<0.05)$. NPY levels normalized by BMI did not correlate significantly with indices of pain sensitivity (i.e., pain threshold or tolerance).

\section{Allopregnanolone and Pregnanolone}

Figure 1(b) shows individual ALLO levels for all participants across the four time points. A repeatedmeasures ANOVA with sphericity assumed revealed significant differences in ALLO levels across time $(F(3,27)$ $=18.01, p<0.001$, partial $\left.\eta^{2}=0.67\right)$; post hoc analyses revealed significant increments in ALLO between successive time points ( $p<0.006$ to 0.001 ). There was not a significant difference in ALLO levels between groups $\left(\mathrm{F}(1,9)=0.83, p=0.39\right.$, partial $\left.\eta^{2}=0.08\right)$ or a significant group by time interaction $(F(3,27)=0.98, p=0.39$, partial $\left.\eta^{2}=0.10\right)$. These latter findings represented medium to large effect sizes, however, suggesting that the lack of 

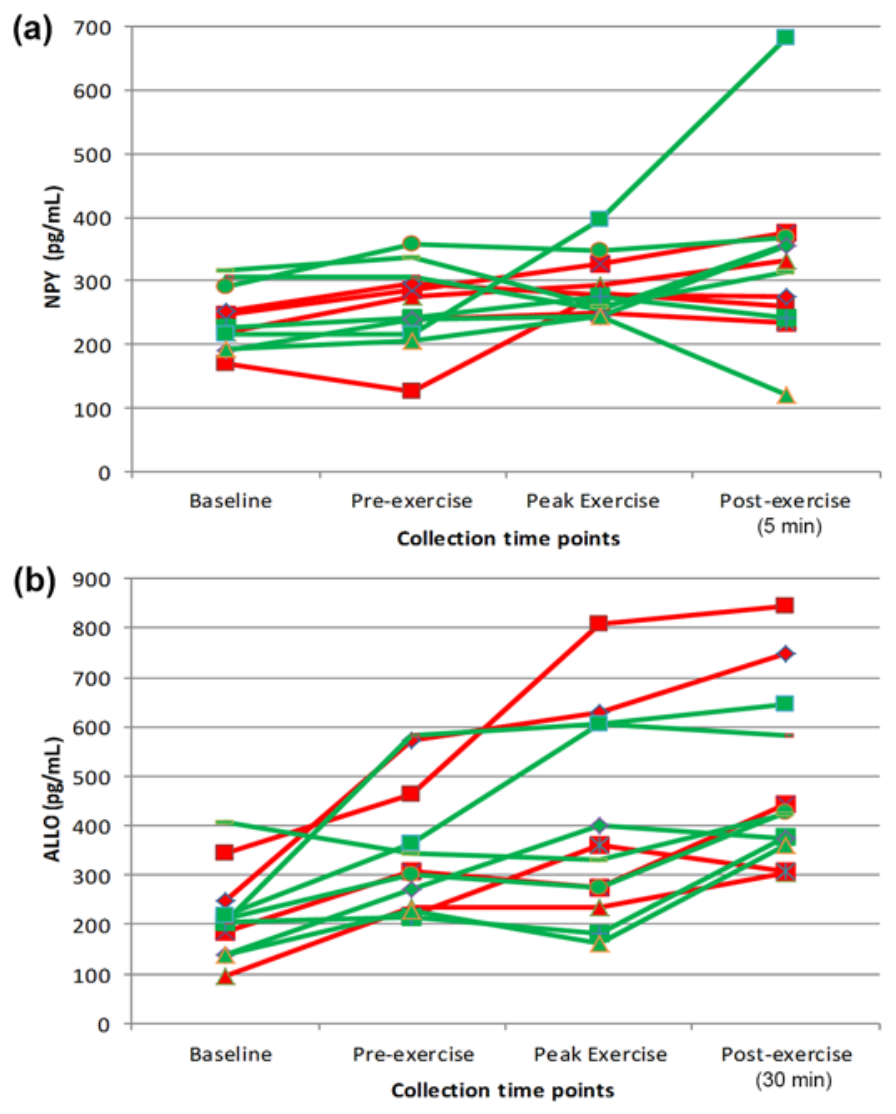

Figure 1.

(a) Plasma neuropeptide Y (NPY) levels for individual participants across four study time points at which it was measured: baseline, pre-exercise, peak of exercise, and 5 min after exercise. (b) Plasma allopregnanolone and pregnanolone (ALLO) levels for individual participants across four time points at which it was measured: baseline, pre-exercise, peak of exercise, and $30 \mathrm{~min}$ after exercise. Red = posttraumatic stress disorder/ chronic pain participants, Green = trauma-exposed healthy participants. Note that pre-exercise cold pressor test was administered between baseline and pre-exercise time points.

statistical significance was due to the small sample size. When these analyses were repeated using BMI as a covariate, there were similar findings across time points: a large effect size for the group by time interaction and a significant group difference $(F(1,8)=7.12, p<0.05)$, such that PTSD participants had higher ALLO levels over time than the TC group.

For all study participants, there was a positive correlation between peak $\mathrm{VO}_{2}$ and peak ALLO measured $30 \mathrm{~min}$ after exercise $(r=0.71, p<0.01)$. There were also posi- tive correlations between $\mathrm{VO}_{2}$ and the increase in ALLO from the baseline and pre-exercise time points to $30 \mathrm{~min}$ after exercise $(r=0.64, p<0.05$ and $r=0.89, p<0.001$, respectively). The increase in ALLO from pre-exercise to 30 min after exercise was positively correlated with pain tolerance after exercise $(r=0.64, p<0.05)$. When ALLO was normalized by BMI, there were no significant correlations with indices of pain sensitivity.

\section{Additional Neuroendocrine Factors}

\section{Cortisol}

Figure 2(a) shows mean cortisol levels by group across the three time points at which it was measured. A repeated-measures ANOVA, using BMI as a covariate and with sphericity assumed, showed no significant change in cortisol levels across time points $(F(2,18)=1.08, p=0.36$, partial $\eta^{2}=0.11$, although there was a large effect size. Nor was there a significant difference in cortisol levels between groups $\left(F(1,9)=0.87, p=0.38\right.$, partial $\left.\eta^{2}=0.09\right)$, although there was a medium to large effect size. There was a trend for a significant group by time interaction $\left(F(2,18)=3.13, p=0.07\right.$, partial $\left.\eta^{2}=0.26\right)$. Peak $\mathrm{VO}_{2}$ was correlated with cortisol levels at all time points: preexercise $(r=0.92, p<0.001), 5 \mathrm{~min}$ after exercise when cortisol peaked $(r=0.55, p<0.07)$, and $30 \mathrm{~min}$ after exercise $(r=0.72, p<0.01)$. The change in cortisol from preexercise to $30 \mathrm{~min}$ after exercise was inversely associated with pain tolerance $30 \mathrm{~min}$ after exercise $(r=-0.62, p<$ $0.05)$. When cortisol was normalized by BMI and correlated with pain sensitivity, the results were similar. Specifically, the change in cortisol from pre-exercise to $30 \mathrm{~min}$ after exercise was inversely correlated with pain tolerance after exercise $(r=-0.69, p<0.05)$.

\section{Dehydroepiandrosterone}

Figure 2(b) shows mean DHEA levels by group across the three time points at which it was measured. A repeatedmeasures ANOVA using age as a covariate and with sphericity assumed showed no significant difference in DHEA levels across time $\left(F(2,18)=1.31, p=0.29\right.$, partial $\eta^{2}=$ $0.13)$, although there was a large effect size. DHEA levels also were not different between groups $(F(1,9)=0.80 p=$ 0.39 , partial $\eta^{2}=0.08$ ), although there was a medium to large effect size. There was a trend for a significant group by time interaction $\left(F(2,18)=4.71, p=0.09\right.$, partial $\eta^{2}=$ 0.24). Peak $\mathrm{VO}_{2}$ was not correlated with DHEA levels. However, similar to the findings for cortisol, the change in 
(a)

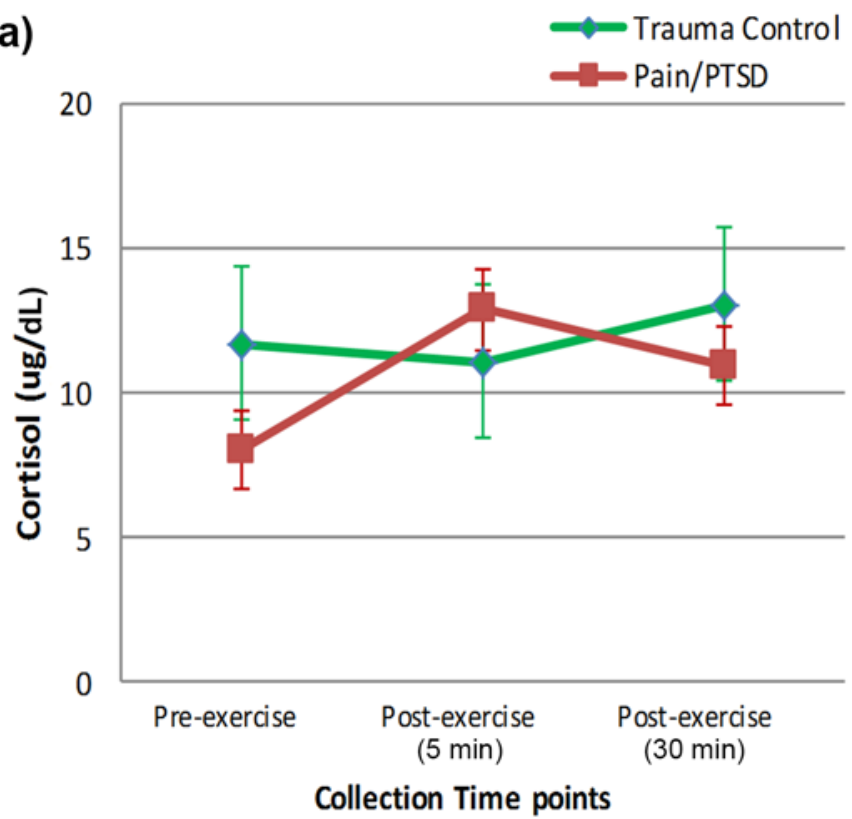

(b)

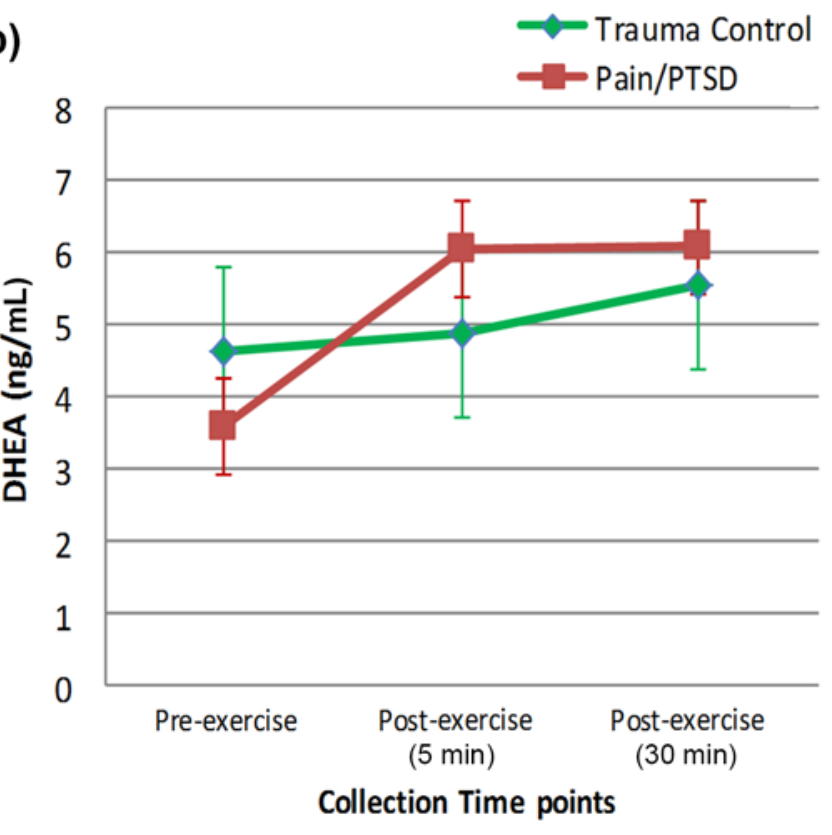

Figure 2.

(a) Plasma cortisol levels and (b) plasma dehydroepiandrosterone (DHEA) levels (mean \pm standard error) by group across three time points at which they were measured: pre-exercise, 5 min after exercise, and $30 \mathrm{~min}$ after exercise. PTSD = posttraumatic stress disorder.

DHEA from pre-exercise to $30 \mathrm{~min}$ after exercise was inversely correlated with pain tolerance after exercise $(r=-0.58, p<0.05)$. DHEA normalized by BMI also correlated with pain tolerance after exercise $(r=-0.58$, $p<0.05)$.

\section{DISCUSSION}

The results of this study demonstrate significant positive correlations between peak $\mathrm{VO}_{2}$ and baseline, as well as peak, NPY levels suggesting that the capacity for NPY synthesis and release is related to cardiorespiratory fitness. Additionally, the peak change in NPY in response to CPX was significantly correlated with pain threshold after exercise. Across biological systems, NPY is known to raise the threshold for release of neurotransmitters with which it is localized by acting at inhibitory presynaptic NPY-Y ${ }_{2}$ receptors [21], suggesting that this mechanism may contribute to its possible acute antinociceptive effects. Effects at upregulated NPY-Y ${ }_{1}$ receptors in the spinal cord in response to acute pain are, in turn, thought to prevent progression of acute pain to chronic pain [13].

As previously noted, we expected there to be group differences in NPY baseline and peak levels achieved in response to CPX. However, there was marked individual variability in NPY levels and responses in both groups and no significant differences between groups or across time points in this small pilot sample. According to Morgan et al., genetic influences and degree of trauma exposure, but not necessarily PTSD diagnosis, are related to lower resting levels of NPY [25], but data in the field are yet lacking with regard to the relationships among NPY genetic factors, trauma exposure, PTSD diagnosis, and NPY reactivity to stress. Future work in larger samples will be required to evaluate these issues.

As demonstrated by Pernow et al., exercise at a mean 70 percent of $\mathrm{VO}_{2}$ peak increases serum NPY in healthy humans [28]. As seen in Figure 1(a), most of the participants in both the chronic pain/PTSD and TC groups (among whom mean fitness was poor) showed only slight increases in plasma NPY from baseline to peak levels measured 5 min after exercise. However, taken together, these findings suggest that even patients with chronic pain/PTSD have the potential to release NPY in response to exercise, with possible effect on pain threshold. Since NPY was correlated with $\mathrm{VO}_{2}$, an index of cardiorespiratory fitness, we hypothesize that progressive exercise training may further increase the capacity for NPY release in patients with chronic pain/PTSD to potentially reduce pain sensitivity and perhaps also improve PTSD symptoms. 
In contrast to the findings for NPY, there were significant progressive increases in ALLO levels across all time points, suggesting that ALLO is released at lower levels of stress intensity. Consistent with work in rodents by Purdy et al. [32], ALLO levels peaked about $60 \mathrm{~min}$ after initiation of stressors, later than for the other neurohormones tested. Consistent with the findings for NPY, we did not find significant group differences in ALLO levels in this small pilot sample. Genetic predisposition and possibly trauma exposure may affect resting ALLO levels as well as the capacity for release of ALLO in response to stress. Thus, further longitudinal research will be needed to sort out the relationships among genetic factors, trauma exposure, PTSD, and alterations in ALLO levels and responses.

For all study participants, there was a significant positive correlation between peak $\mathrm{VO}_{2}$ and the change in ALLO from baseline to $30 \mathrm{~min}$ after exercise. Similar to NPY, these findings suggest that the capacity to release ALLO is related to cardiorespiratory fitness. The change in ALLO between baseline and $30 \mathrm{~min}$ after exercise was also significantly correlated with pain tolerance after exercise. This finding is consistent with work by Sripada et al. demonstrating reductions in activity of the amygdala and insula, areas central to the experience of pain, in association with experimentally induced increases in plasma levels of allopregnanolone [44]. In addition, allopregnanolone enhanced dorsal medial prefrontal cortex activity and the connectivity between dorsal medial prefrontal cortex and amygdala in association with reductions in anxiety - thus demonstrating a significant role for allopregnanolone in emotion regulation, a construct likely related to pain tolerance.

There were large effect sizes for PTSD/chronic pain versus TC group differences in DHEA and cortisol levels generally, expected medium to large effect sizes for increases in response to exercise for both groups (Figure 2), and a trend for increased DHEA responding in the PTSD group, which could in part be related to greater trauma exposure in that group [47-48]. However, for all study participants, acute exercise-induced increases in both cortisol and DHEA were inversely correlated with pain tolerance after exercise. We suggest that possible pharmacological effects of DHEA that counter those of ALLO [15] and direct detrimental effects of cortisol on the balance between prefrontal cortical [49] and amygdala reactivity [50] may underlie this finding.

Finally, it is important to briefly discuss the significant difference found between study groups for BMI. While the
pain/PTSD group had a significantly greater mean BMI than the TC group, both groups contained individuals at the high end of the BMI range. This finding is not surprising given that obesity continues to be a significant health problem in the U.S. general population [51]. The pain/ PTSD group had a BMI consistent with obesity category III, and most of these participants were Veterans. Among Veterans in Veterans Health Administration care, obesity is more prevalent than for non-Veterans. Multiple morbidities such as pain, PTSD, and obesity are more likely to adversely affect overall health, functioning, and quality of life for these individuals [51-57]. In fact, additional research has focused on the mediating role of trauma exposure or PTSD and related neurobiological factors in adverse health conditions such as metabolic syndrome [56]. Given that exercise is beneficial for the treatment of such adverse health conditions, including chronic pain, the investigation of exercise as a potential multisystem treatment intervention for men and women suffering from chronic pain and PTSD is compelling.

\section{IMPLICATIONS}

Restoring normal NPY and ALLO levels and responses to stress could help with the management of chronic pain in a PTSD population. As reviewed by Scioli-Salter et al. [13], pain can trigger memories as well as emotional and physiological reexperiencing of a trauma by activating the amygdala via sensory projections routed through the thalamus and parabrachial nucleus. Activation of the amygdala, in turn, can affect pain sensitivity by increasing molecular substrates in the dorsal horn of the spinal cord that facilitate transmission of pain from the periphery. Thus, trauma cues or pain experiences that activate the amygdala may progressively intensify the simultaneous experience of PTSD reexperiencing symptoms and peripheral pain. Thus, neurobiological factors, such as NPY and ALLO that both diminish the reactivity of the amygdala and directly diminish pain transmission in the spinal cord, may reduce both pain sensitivity and PTSD symptoms. In fact, when hyperreactivity of the amygdala is diminished, frontal lobe function and frontal lobe inhibition of the amygdala also improve. This may further enhance pain tolerance and allow for higher-order cognitive processing, which may, in turn, promote recovery from traumatic stress.

Therefore, given our observation of the strong relationship between fitness and exercise-induced increases in NPY 
and ALLO, we hypothesize that exercise training could complement and improve the efficacy of cognitive-based treatments for both chronic pain and PTSD by increasing the capacity for release of these molecules. This is supported by recent work showing that $2 \mathrm{wk}$ of moderate aerobic exercise training in already fit male rowers further increased the capacity for NPY release in response to a subsequent acute exercise challenge [29]. In addition, exercise has been shown to enhance vagal parasympathetic neurotransmission and thereby suppress proinflammatory pathways - another pathway by which chronic pain might be improved. Furthermore, progressive exercise training focused on reaching biological targets such as raising plasma levels of NPY and ALLO may help to break the vicious circle between pain and pain-avoidance behaviors (including avoidance of exercise). Exercise-related reductions in pain and perhaps reestablishment of exercise-induced reward potentially mediated by NPY [57-59] may also serve to enhance intrinsic motivation and maintenance of exercise.

\section{CONCLUSIONS}

Our pilot work in trauma-exposed individuals with and without PTSD/chronic pain shows a strong, positive relationship between postexercise pain threshold and plasma NPY and between pain tolerance and ALLO levels and responses, as well as a strong, inverse relationship between pain tolerance and exercise-induced changes in plasma cortisol and DHEA levels. Exercise-related changes in these neurohormones were also related to cardiorespiratory fitness. These pilot study findings thus suggest that progressive exercise training could potentially increase the capacity for release of NPY and ALLO in response to exercise challenge, if not in response to stress more generally, and thereby reduce pain sensitivity in a chronic pain and PTSD population. We are currently testing these hypotheses using symptom-limited CPX before and after a $12 \mathrm{wk}$ individualized progressive exercise training program in traumaexposed Veterans with and without chronic pain/PTSD. Defining the biology underlying exercise-related improvements in pain in populations with chronic pain and PTSD may help optimize implementation of exercise programs for this population, as well as guide development of other novel pharmacological and nonpharmacological therapies to reduce suffering and disability in this population.

\section{ACKNOWLEDGMENTS}

\section{Author Contributions:}

Study concept and design: E. Scioli-Salter, A. M. Rasmusson, D. E. Forman, J. D. Otis, C. Tun.

Acquisition of data: E. Scioli-Salter, K. Allsup, C. Tun. Analysis and interpretation of data: E. Scioli-Salter, A. M. Rasmusson.

Drafting of manuscript: E. Scioli-Salter, A. M. Rasmusson,

D. E. Forman, J. D. Otis.

Critical revision of manuscript for important intellectual content:

E. Scioli-Salter, A. M. Rasmusson, D. E. Forman, J. D. Otis,

C. E. Marx, R. L. Hauger, J. C. Shipherd, D. M. Higgins.

Statistical analysis: E. Scioli-Salter, A. M. Rasmusson.

Obtained funding: E. Scioli-Salter, A. M. Rasmusson.

Administrative, technical, or material support: A. Tyzik, K. Allsup.

Study supervision: E. Scioli-Salter, A. M. Rasmusson, J. D. Otis, D. E. Forman.

Financial Disclosures: The authors have declared that no competing interests exist.

Funding/Support: This material was based on work supported in part by the VA Rehabilitation Research and Development Service (award 1IK2RX000704-01A2); the Women's Health Sciences Division, National Center for PTSD; the National Institute of Aging (grant RO1 AG050595-01); VA Merit Review (award CAMM-001-125); the VA Center of Excellence for Stress and Mental Health; and the Durham VA Medical Center. The Stress Neuroendocrinology Core of the VA San Diego Healthcare System Research Service, directed by Dr. Hauger, performed the NPY and DHEA(S) immunoassays for this study. The Interventions and Metabolomics Laboratory of the VA Mid-Atlantic Mental Illness Research, Education and Clinical Center, directed by Dr. Marx, quantified neurosteroid levels via gas chromatography/mass spectrometry.

Institutional Review: The institutional review board of the VA Boston Healthcare System-Jamaica Plain Campus approved this work.

Additional Contributions: D. E. Forman is now with the Division of Cardiology, University of Pittsburgh Medical Center, VA Pittsburgh Healthcare System, Pittsburgh, Pennsylvania. K. Allsup is now with the Research Division, VA Pittsburgh Healthcare System, Pittsburgh, Pennsylvania.

Participant Follow-Up: The authors do not plan to inform participants of the publication of this study.

\section{REFERENCES}

1. Otis JD, Keane TM, Kerns RD. An examination of the relationship between chronic pain and post-traumatic stress disorder. J Rehabil Res Dev. 2003;40(5):397-405.

[PMID:15080224]

http://dx.doi.org/10.1682/JRRD.2003.09.0397

2. Asmundson GJ, Coons MJ, Taylor S, Katz J. PTSD and the experience of pain: Research and clinical implications of shared vulnerability and mutual maintenance models. Can J Psychiatry. 2002;47(10):930-37. [PMID:12553128] 
3. Geisser ME, Roth RS, Bachman JE, Eckert TA. The relationship between symptoms of post-traumatic stress disorder and pain, affective disturbance and disability among patients with accident and non-accident related pain. Pain. 1996;66(2-3):207-14. [PMID:8880842] http://dx.doi.org/10.1016/0304-3959(96)03038-2

4. Scioli ER, Otis JD, Keane TM. Psychological problems associated with OEF/OIF deployment. Am J Lifestyle Med. 2010;4(4):349-59. http://dx.doi.org/10.1177/1559827610362962

5. Shipherd JC, Keyes M, Jovanovic T, Ready DJ, Baltzell D, Worley V, Gordon-Brown V, Hayslett C, Duncan E. Veterans seeking treatment for posttraumatic stress disorder: What about comorbid chronic pain? J Rehabil Res Dev. 2007;44(2):153-66. [PMID:17551870] http://dx.doi.org/10.1682/JRRD.2006.06.0065

6. Beckham JC, Crawford AL, Feldman ME, Kirby AC, Hertzberg MA, Davidson JR, Moore SD. Chronic posttraumatic stress disorder and chronic pain in Vietnam combat veterans. J Psychosom Res. 1997;43(4):379-89. [PMID:9330237] http://dx.doi.org/10.1016/S0022-3999(97)00129-3

7. Lew HL, Otis JD, Tun C, Kerns RD, Clark ME, Cifu DX. Prevalence of chronic pain, posttraumatic stress disorder, and persistent postconcussive symptoms in OIF/OEF veterans: Polytrauma clinical triad. J Rehabil Res Dev. 2009; 46(6):697-702. [PMID:20104399]

http://dx.doi.org/10.1682/JRRD.2009.01.0006

8. Cifu DX, Taylor BC, Carne WF, Bidelspach D, Sayer NA, Scholten J, Campbell EH. Traumatic brain injury, posttraumatic stress disorder, and pain diagnoses in OIF/OEF/OND Veterans. J Rehabil Res Dev. 2013;50(9):1169-76. [PMID:24458958] http://dx.doi.org/10.1682/JRRD.2013.01.0006

9. Elliott AM, Smith BH, Penny KI, Smith WC, Chambers WA. The epidemiology of chronic pain in the community. Lancet. 1999;354(9186):1248-52. [PMID:10520633] http://dx.doi.org/10.1016/S0140-6736(99)03057-3

10. Asmundson GJ, Taylor S. Role of anxiety sensitivity in pain-related fear and avoidance. J Behav Med. 1996;19(6): 577-86. [PMID:8970916] http://dx.doi.org/10.1007/BF01904905

11. Norton PJ, Asmundson GJ. Anxiety sensitivity, fear, and avoidance behavior in headache pain. Pain. 2004;111(1-2): 218-23. [PMID:15327826] http://dx.doi.org/10.1016/j.pain.2004.06.018

12. Sharp TJ, Harvey AG. Chronic pain and posttraumatic stress disorder: Mutual maintenance? Clin Psychol Rev. 2001;21(6):857-77. [PMID:11497210] http://dx.doi.org/10.1016/S0272-7358(00)00071-4

13. Scioli-Salter ER, Forman DE, Otis JD, Gregor K, Valovski I, Rasmusson AM. The shared neuroanatomy and neurobi- ology of comorbid chronic pain and PTSD: Therapeutic implications. Clin J Pain. 2015;31(4):363-74.

[PMID:24806468]

http://dx.doi.org/10.1097/AJP.0000000000000115

14. Matsumoto K, Puia G, Dong E, Pinna G. GABA(A) receptor neurotransmission dysfunction in a mouse model of social isolation-induced stress: Possible insights into a nonserotonergic mechanism of action of SSRIs in mood and anxiety disorders. Stress. 2007;10(1):3-12.

[PMID:17454962]

http://dx.doi.org/10.1080/10253890701200997

15. Mechlin B, Morrow AL, Maixner W, Girdler SS. The relationship of allopregnanolone immunoreactivity and HPAaxis measures to experimental pain sensitivity: Evidence for ethnic differences. Pain. 2007;131(1-2):142-52. [PMID: 17292548$]$ http://dx.doi.org/10.1016/j.pain.2006.12.027

16. Rasmusson AM, Pinna G, Paliwal P, Weisman D, Gottschalk C, Charney D, Krystal J, Guidotti A. Decreased cerebrospinal fluid allopregnanolone levels in women with posttraumatic stress disorder. Biol Psychiatry. 2006;60(7): 704-13. [PMID:16934764] http://dx.doi.org/10.1016/j.biopsych.2006.03.026

17. Li JJ, Zhou X, Yu LC. Involvement of neuropeptide Y and $\mathrm{Y} 1$ receptor in antinociception in the arcuate nucleus of hypothalamus, an immunohistochemical and pharmacological study in intact rats and rats with inflammation. Pain. 2005;118(1-2):232-42. [PMID:16216414] http://dx.doi.org/10.1016/j.pain.2005.08.023

18. Taiwo OB, Taylor BK. Antihyperalgesic effects of intrathecal neuropeptide $\mathrm{Y}$ during inflammation are mediated by Y1 receptors. Pain. 2002;96(3):353-63. [PMID:11973010] http://dx.doi.org/10.1016/S0304-3959(01)00481-X

19. Zukowska-Grojec Z. Neuropeptide Y. A novel sympathetic stress hormone and more. Ann N Y Acad Sci. 1995;771: 219-33. [PMID:8597401] http://dx.doi.org/10.1111/j.1749-6632.1995.tb44683.x

20. Taylor BK. NPY analgesia: Moving from acute to chronic pain. In: Zukowska Z, Feuerstein GZ, editors. The NPY family of peptides in immune disorders, inflammation, angiogenesis and cancer. Boston (MA): Birkhäuser Verlag; 2005. p. 135-48.

21. Rasmusson AM, Hauger RL, Morgan CA III, Bremner JD, Charney DS, Southwick SM. Low baseline and yohimbinestimulated plasma neuropeptide Y (NPY) levels in combatrelated PTSD. Biol Psychiatry. 2000;47(6):526-39. [PMID:10715359] http://dx.doi.org/10.1016/S0006-3223(99)00185-7

22. Sah R, Geracioti TD. Neuropeptide Y and posttraumatic stress disorder. Mol Psychiatry. 2013;18(6):646-55. [PMID:22801411] http://dx.doi.org/10.1038/mp.2012.101 
23. Morgan CA 3rd, Wang S, Southwick SM, Rasmusson A, Hazlett G, Hauger RL, Charney DS. Plasma neuropeptide-Y concentrations in humans exposed to military survival training. Biol Psychiatry. 2000;47(10):902-9.

[PMID:10807963] http://dx.doi.org/10.1016/S0006-3223(99)00239-5

24. Morgan CA 3rd, Rasmusson AM, Wang S, Hoyt G, Hauger RL, Hazlett G. Neuropeptide-Y, cortisol, and subjective distress in humans exposed to acute stress: Replication and extension of previous report. Biol Psychiatry. 2002;52(2): 136-42. [PMID:12114005] http://dx.doi.org/10.1016/S0006-3223(02)01319-7

25. Morgan CA 3rd, Rasmusson AM, Winters B, Hauger RL, Morgan J, Hazlett G, Southwick S. Trauma exposure rather than posttraumatic stress disorder is associated with reduced baseline plasma neuropeptide-Y levels. Biol Psychiatry. 2003;54(10):1087-91. [PMID:14625151] http://dx.doi.org/10.1016/S0006-3223(03)00433-5

26. Melzack R. Pain and the neuromatrix in the brain. J Dent Educ. 2001;65(12):1378-82. [PMID:11780656]

27. Pitman RK, Rasmusson AM, Koenen KC, Shin LM, Orr SP, Gilbertson MW, Milad MR, Liberzon I. Biological studies of post-traumatic stress disorder. Nat Rev Neurosci. 2012;13(11):769-87. [PMID:23047775]

http://dx.doi.org/10.1038/nrn3339

28. Pernow J, Lundberg JM, Kaijser L, Hjemdahl P, Theodorsson-Norheim E, Martinsson A, Pernow B. Plasma neuropeptide Y-like immunoreactivity and catecholamines during various degrees of sympathetic activation in man. Clin Physiol. 1986;6(6):561-78. [PMID:3466738] http://dx.doi.org/10.1111/j.1475-097X.1986.tb00789.x

29. Rämson R, Jürimäe J, Jürimäe T, Mäestu J. The effect of 4week training period on plasma neuropeptide $\mathrm{Y}$, leptin and ghrelin responses in male rowers. Eur J Appl Physiol. 2012;112(5):1873-80. [PMID:21922260] http://dx.doi.org/10.1007/s00421-011-2166-y

30. Beckley EH, Finn DA. Inhibition of progesterone metabolism mimics the effect of progesterone withdrawal on forced swim test immobility. Pharmacol Biochem Behav. 2007;87(4):412-19. [PMID:17597197] http://dx.doi.org/10.1016/j.pbb.2007.05.017

31. Frye CA, Walf AA. Changes in progesterone metabolites in the hippocampus can modulate open field and forced swim test behavior of proestrous rats. Horm Behav. 2002;41(3): 306-15. [PMID:11971664] http://dx.doi.org/10.1006/hbeh.2002.1763

32. Purdy RH, Morrow AL, Moore PH Jr, Paul SM. Stressinduced elevations of gamma-aminobutyric acid type A receptor-active steroids in the rat brain. Proc Natl Acad Sci USA. 1991;88(10):4553-57. [PMID:1852011] http://dx.doi.org/10.1073/pnas.88.10.4553
33. Sánchez P, Torres JM, Gavete P, Ortega E. Effects of swim stress on mRNA and protein levels of steroid 5alphareductase isozymes in prefrontal cortex of adult male rats. Neurochem Int. 2008;52(3):426-31. [PMID:17826869] http://dx.doi.org/10.1016/j.neuint.2007.07.019

34. He X, Zhao M, Bi X, Yu X, Zhao M, Zang W. Novel strategies and underlying protective mechanisms of modulation of vagal activity in cardiovascular disease. Br J Pharmacol. 2014. Epub ahead of print. [PMID:25378088]

35. Friedman MJ, Keane TM, Resick PA. Handbook of PTSD: Science and practice. New York (NY): Guilford Press; 2007.

36. Blake DD, Weathers FW, Nagy LM, Kaloupek DG, Klauminzer G, Charney DS, Keane TM. A clinician rating scale for assessing current and lifetime PTSD: The CAPS-1. Behav Ther. 1990;13(8):187-88.

37. First MB, Spitzer RL, Gibbon M, Williams JB. Structured clinical interview for DSM-IV axis I disorders, clinician version (SCID-CV). Washington (DC): American Psychiatric Press; 1996.

38. Hellström B, Lundberg U. Pain perception to the cold pressor test during the menstrual cycle in relation to estrogen levels and a comparison with men. Integr Physiol Behav Sci. 2000;35(2):132-41. [PMID:11021338] http://dx.doi.org/10.1007/BF02688772

39. McRae AL, Saladin ME, Brady KT, Upadhyaya H, Back SE, Timmerman MA. Stress reactivity: Biological and subjective responses to the cold pressor and Trier Social stressors. Hum Psychopharmachol. 2006;21(6):377-85.

[PMID:16915579]

http://dx.doi.org/10.1002/hup.778

40. Tanriverdi F, Karaca Z, Unluhizarci K, Kelestimur F. The hypothalamo-pituitary-adrenal axis in chronic fatigue syndrome and fibromyalgia syndrome. Stress. 2007;10(1):13-25. [PMID: 17454963] http://dx.doi.org/10.1080/10253890601130823

41. Fletcher GF, Balady GJ, Amsterdam EA, Chaitman B, Eckel R, Fleg J, Froelicher VF, Leon AS, Piña IL, Rodney R, Simons-Morton DA, Williams MA, Bazzarre T. Exercise standards for testing and training: A statement for healthcare professionals from the American Heart Association. J Circulation. 2001;104(14):1694-1740. [PMID:11581152] http://dx.doi.org/10.1161/hc3901.095960

42. Beaver WL, Wasserman K, Whipp BJ. A new method for detecting anaerobic threshold by gas exchange. J Appl Physiol. 1986;60(6):2020-27. [PMID:3087938]

43. Marx CE, Trost WT, Shampine L, Behm FM, Giordano LA, Massing MW, Rose JE. Neuroactive steroids, negative affect, and nicotine dependence severity in male smokers. Psychopharmacology (Berl). 2006;186(3):462-72.

[PMID:16402195] http://dx.doi.org/10.1007/s00213-005-0226-x 
44. Sripada RK, Marx CE, King AP, Rampton JC, Ho SS, Liberzon I. Allopregnanolone elevations following pregnenolone administration are associated with enhanced activation of emotion regulation neurocircuits. Biol Psychiatry. 2013;73(11):1045-53. [PMID:23348009] http://dx.doi.org/10.1016/j.biopsych.2012.12.008

45. Morgan CA 3rd, Rasmusson A, Pietrzak RH, Coric V, Southwick SM. Relationships among plasma dehydroepiandrosterone and dehydroepiandrosterone sulfate, cortisol, symptoms of dissociation, and objective performance in humans exposed to underwater navigation stress. Biol Psychiatry. 2009;66(4):334-40. [PMID:19500775] http://dx.doi.org/10.1016/j.biopsych.2009.04.004

46. Cohen J. A power primer. Psychol Bull. 1992;112(1):155-59. [PMID:19565683] http://dx.doi.org/10.1037/0033-2909.112.1.155

47. Söndergaard HP, Hansson L-O, Theorell T. Elevated blood levels of dehydroepiandrosterone sulphate vary with symptom load in posttraumatic stress disorder: Findings from a longitudinal study of refugees in Sweden. Psychother Psychosom. 2002;71(5):298-303. [PMID:12207110]

http://dx.doi.org/10.1159/000064806

48. Rasmusson AM, Vasek J, Lipschitz DS, Vojvoda D, Mustone ME, Shi Q, Gudmundsen G, Morgan CA, Wolfe J, Charney DS. An increased capacity for adrenal DHEA release is associated with decreased avoidance and negative mood symptoms in women with PTSD. Neuropsychopharmacology. 2004;29(8):1546-57. [PMID:15199367] http://dx.doi.org/10.1038/sj.npp.1300432

49. Lupien SJ, Gillin CJ, Hauger RL. Working memory is more sensitive than declarative memory to the acute effects of corticosteroids: A dose-response study in humans. Behav Neurosci. 1999;113(3):420-30. [PMID:10443770] http://dx.doi.org/10.1037/0735-7044.113.3.420

50. Schulkin J, Gold PW, McEwen BS. Induction of corticotropin-releasing hormone gene expression by glucocorticoids: Implication for understanding the states of fear and anxiety and allostatic load. Psychoneuroendocrinology. 1998;23(3): 219-43. [PMID:9695128]

http://dx.doi.org/10.1016/S0306-4530(97)00099-1

51. Yanovski SZ, Yanovski JA. Obesity prevalence in the United States-Up, down, or sideways? N Engl J Med. 2011;364(11):987-89. [PMID:21410367]

http://dx.doi.org/10.1056/NEJMp1009229

52. Das SR, Kinsinger LS, Yancy WS Jr, Wang A, Ciesco E, Burdick M, Yevich SJ. Obesity prevalence among veterans at Veterans Affairs medical facilities. Am J Prev Med. 2005;28(3):291-94. [PMID:15766618] http://dx.doi.org/10.1016/j.amepre.2004.12.007

53. Rasmusson AM, Schnurr PP, Zukowska Z, Scioli E, Forman DE. Adaptation to extreme stress: Post-traumatic stress disorder, neuropeptide Y and metabolic syndrome. Exp Biol Med
(Maywood). 2010;235(10):1150-62. [PMID:20881319]

http://dx.doi.org/10.1258/ebm.2010.009334

54. Kuo LE, Kitlinska JB, Tilan JU, Li L, Baker SB, Johnson MD, Lee EW, Burnett MS, Fricke ST, Kvetnansky R, Herzog H, Zukowska Z. Neuropeptide $\mathrm{Y}$ acts directly in the periphery on fat tissue and mediates stress-induced obesity and metabolic syndrome. Nat Med. 2007;13(7):803-11. [PMID:17603492] http://dx.doi.org/10.1038/nm1611

55. Schnurr PP, Spiro A 3rd. Combat exposure, posttraumatic stress disorder symptoms, and health behaviors as predictors of self-reported physical health in older veterans. J Nerv Ment Dis. 1999;187(6):353-59. [PMID:10379722] http://dx.doi.org/10.1097/00005053-199906000-00004

56. Jakovljević M, Sarić M, Nad S, Topić R, Vuksan-Cusa B. Metabolic syndrome, somatic and psychiatric comorbidity in war veterans with post-traumatic stress disorder: Preliminary findings. Psychiatr Danub. 2006;18(3-4):169-76. [PMID:17099607]

57. Southwick SM, Krystal JH, Morgan CA, Johnson D, Nagy LM, Nicolaou A, Heninger GR, Charney DS. Abnormal noradrenergic function in posttraumatic stress disorder. Arch Gen Psychiatry. 1993;50(4):266-74. [PMID:8466387] http://dx.doi.org/10.1001/archpsyc.1993.01820160036003

58. Josselyn SA, Beninger RJ. Neuropeptide Y: Intraaccumbens injections produce a place preference that is blocked by cis-flupenthixol. Pharmacol Biochem Behav. 1993; 46(3):543-52. [PMID:8278431] http://dx.doi.org/10.1016/0091-3057(93)90542-2

59. Brown CM, Coscina DV, Fletcher PJ. The rewarding properties of neuropeptide $\mathrm{Y}$ in perifornical hypothalamus vs. nucleus accumbens. Peptides. 2000;21(8):1279-87.

[PMID:11035216]

http://dx.doi.org/10.1016/S0196-9781(00)00270-9

Submitted for publication October 30, 2014. Accepted in revised form May 29, 2015.

This article and any supplementary material should be cited as follows:

Scioli-Salter E, Forman DE, Otis JD, Tun C, Allsup K, Marx CE, Hauger RL, Shipherd JC, Higgins DM, Tyzik A, Rasmusson AM. Potential neurobiological benefits of exercise in chronic pain and posttraumatic stress disorder: Pilot study. J Rehabil Res Dev. 2016;53(1):95-106. http://dx.doi.org/10.1682/JRRD.2014.10.0267

ORCID: Diana M. Higgins, PhD; 0000-0002-6885-266X

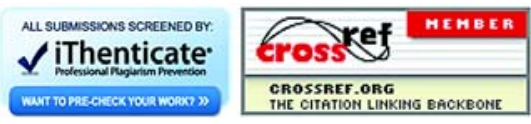

